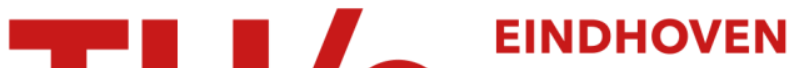

\section{An improved one-dimensional model for liquid slugs travelling in pipelines}

\section{Citation for published version (APA):}

Tijsseling, A. S., Hou, Q., \& Bozkus, Z. (2016). An improved one-dimensional model for liquid slugs travelling in pipelines. Journal of Pressure Vessel Technology. Transactions of the ASME, 138(1), 011301-1/8.

https://doi.org/10.1115/1.4029794

\section{Document license:}

TAVERNE

DOI:

10.1115/1.4029794

Document status and date:

Published: 01/01/2016

\section{Document Version:}

Publisher's PDF, also known as Version of Record (includes final page, issue and volume numbers)

\section{Please check the document version of this publication:}

- A submitted manuscript is the version of the article upon submission and before peer-review. There can be important differences between the submitted version and the official published version of record. People interested in the research are advised to contact the author for the final version of the publication, or visit the $\mathrm{DOI}$ to the publisher's website.

- The final author version and the galley proof are versions of the publication after peer review.

- The final published version features the final layout of the paper including the volume, issue and page numbers.

Link to publication

\section{General rights}

Copyright and moral rights for the publications made accessible in the public portal are retained by the authors and/or other copyright owners and it is a condition of accessing publications that users recognise and abide by the legal requirements associated with these rights.

- Users may download and print one copy of any publication from the public portal for the purpose of private study or research.

- You may not further distribute the material or use it for any profit-making activity or commercial gain

- You may freely distribute the URL identifying the publication in the public portal.

If the publication is distributed under the terms of Article 25fa of the Dutch Copyright Act, indicated by the "Taverne" license above, please follow below link for the End User Agreement:

www.tue.nl/taverne

Take down policy

If you believe that this document breaches copyright please contact us at:

openaccess@tue.nl

providing details and we will investigate your claim. 


\section{Arris S. Tijsseling ${ }^{1}$ \\ Department of Mathematics \\ and Computer Science, \\ Eindhoven University of Technology, \\ P.0. Box 513 \\ 5600 MB Eindhoven, The Netherlands \\ e-mail: a.s.tijsseling@tue.nl \\ Qingzhi Hou \\ and Technology, \\ State Key Laboratory of Hydraulic Engineering, \\ An Improved One-Dimensional Model for Liquid Slugs Traveling in Pipelines}

Simulation, and Safety,

Tianjin University,

Tianjin 300072, China

e-mail: qhou@tju.edu.cn

Zafer Bozkus

Hydromechanics Laboratory,

Department of Civil Engineering,

Middle East Technical University,

Ankara 06800, Turkey

e-mail: bozkus@metu.edu.tr

An improved one-dimensional (1D) model-compared to previous work by the authorsis proposed, which is able to predict the acceleration and shortening of a single liquid slug propagating in a straight pipe with a downstream bend. The model includes holdup at the slug's tail and flow separation at the bend. The obtained analytical and numerical results are validated against experimental data. The effects of holdup, driving pressure and slug length are examined in a parameter variation study. [DOI: 10.1115/1.4029794]

\section{Introduction}

Isolated liquid slugs traveling in pipelines form a potential danger that needs to be assessed. The slugs may accelerate to high velocities and damage pipe anchors and hydraulic machinery when hitting obstructions like bends and valves. The impact force is proportional to the square of the slug's speed, and the impact duration is proportional to the slug's length and inversely proportional to its speed. Therefore, a good assessment of both speed and length is essential in risk and postaccident analyses.

A thoughtful analysis based on physical principles, simple examples, and parameter variation is presented. This approach leads to more insight than the straightforward use of standard software and usually gives more clues on how to fix problems or adjust system behavior. A literature review of the subject has been given in Ref. [1]. An alternative derivation (using Leibniz's rule) and refinement of the 1D model used in Refs. [1,2] is presented in the Appendix. The refinement is that-in the equation of motion-the slug velocity is not taken uniform, but linearly increasing from front to tail. Symbolic solutions are provided for slugs in inclined pipes driven by a constant pressure difference. The results of numerical simulations are compared with the laboratory measurements presented in Ref. [3].

\section{Slug Motion}

Consider the schematized liquid slug traveling at speed $v$ in a straight pipe with circular cross section $A$ as sketched in Fig. 1. The planar front is at position $x_{1}$ and the planar tail is at position $x_{2}$. The pressure is $P_{1}$ at the front of the slug and $P_{2}$ at its tail. The traveling slug leaves liquid behind which is referred to as holdup (or mass shedding). The amount of holdup is proportional to a coefficient $\beta$ to be defined later. The slug has mass $m$, length $L$, and constant density $\rho$ related by

$$
m=\rho A L
$$

\footnotetext{
Corresponding author.

Contributed by the Pressure Vessel and Piping Division of ASME for publication in the Journal of Pressure Vessel Technology. Manuscript received November 6, 2014; final manuscript received February 4, 2015; published online August 25, 2015. Assoc. Editor: Jong Chull Jo.
}

For the sake of clarity, three propulsion and four resistance mechanisms are identified. These are:

Propulsion:

(1) When there is a positive pressure difference between slug tail and front, and there is no holdup, the slug accelerates according to $a=\left(P_{2}-P_{1}\right) A / m$.

(2) When there is no pressure difference between slug tail and front, but there is stationary holdup, the slug acceleration is $a=-(v / m) \mathrm{d} m / \mathrm{d} t$; that is, both $a$ and $v$ increase because $m$ decreases.

(3) Gravity in downward sloping pipes (with angle $\theta$ ) gives an acceleration $a=g \sin \theta$

Resistance:

(1) Gravity in an upward sloping pipe

(2) Skin friction and turbulence

(3) Pressure build-up in front of the slug due to entrapped air upstream (this may even cause a negative pressure difference)

(4) The slug may pick up additional liquid on its way.

The slug may break up because of obstacles and/or air entrainment. It is not (yet) clear what the effect of air entrainment on slug acceleration is.

To explain the key mechanisms of slug motion two idealized cases are considered, before introducing the 1D model developed in this paper.

Frictional Acceleration Without Holdup. For a slug driven by a constant pressure difference and gravity, and opposed by quasi-steady turbulent friction, the governing equation is

$$
\frac{\mathrm{d} v}{\mathrm{~d} t}=\frac{P_{2}-P_{1}}{\rho L_{0}}+g \sin \theta-\frac{f}{2 D} v^{2}
$$

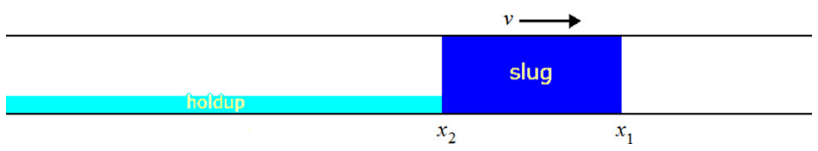

Fig. 1 Sketch of slug propagation 
where $L_{0}$ is the initial slug length which remains constant when there is no holdup. The analytical solution is [4,5]

$$
v(t)=v_{\infty} \tanh \left(\operatorname{artanh}\left(v_{0} / v_{\infty}\right)+\sqrt{C_{1} C_{2}} t\right)
$$

with $C_{1}:=\left(P_{2}-P_{1}\right) /\left(\rho L_{0}\right)+g \sin \theta>0, C_{2}:=f / 2 D, v_{\infty}=v(\infty)=$ $\sqrt{C_{1} / C_{2}}, v_{0}=v(0)=$ the initial velocity at $t=0, D=$ pipe diameter, and $f=$ Darcy-Weisbach friction coefficient.

The distance traveled from $x(0)=0$ is

$$
x(t)=\int_{0}^{t} v(t) \mathrm{d} t=\frac{1}{C_{2}} \ln \left(\cosh \left(\operatorname{artanh}\left(v_{0} / v_{\infty}\right)+\sqrt{C_{1} C_{2}} t\right)\right)
$$

Slug arrival times follow from the inverse of relation $(4 a)$

$$
t(x)=\frac{1}{\sqrt{C_{1} C_{2}}}\left(\operatorname{arcosh}\left(e^{C_{2} x}\right)-\operatorname{artanh}\left(v_{0} / v_{\infty}\right)\right)
$$

The velocity of the slug when it has traveled a distance $L_{\text {pipe }}$ (length scale of the pipeline) is derived from Eqs. (3) and (4b) as

$$
v\left(t\left(L_{\text {pipe }}\right)\right)=v_{\infty} \sqrt{1-e^{-2 C_{2} L_{\text {pipe }}}}
$$

The formulas (3)-(5) provide insight in the time and length scales involved, give order-of-magnitude estimates, and they can be used to validate numerical solutions.

Frictionless Acceleration With Holdup. Even if there is no pressure difference across the slug and the pipe is horizontal, a moving slug will accelerate when it loses mass. This selfpropulsion is similar to that of a space rocket and the same governing equation applies [6]

$$
\frac{\mathrm{d} v}{\mathrm{~d} t}=-\frac{v}{m} \frac{\mathrm{d} m}{\mathrm{~d} t}
$$

It is assumed that the holdup is stationary, meaning that it has zero velocity, so that its velocity relative to the slug is $-v$ and the acceleration is maximal. Substituting Eq. (1) in Eq. (6) gives

$$
L \frac{\mathrm{d} v}{\mathrm{~d} t}=-v \frac{\mathrm{d} L}{\mathrm{~d} t}=-v\left(v_{1}-v_{2}\right)
$$

where $v_{1}$ and $v_{2}$ are the velocities of the slug front and tail, respectively, (Fig. 1) and $L=x_{1}-x_{2}$. Replacing the velocity $v$ in $\mathrm{d} v / \mathrm{d} t$ on the left by the centroid velocity $\left(v_{1}+v_{2}\right) / 2$ and the velocity $v$ on the right by $v_{1}$, one obtains

$$
\frac{L}{2}\left(\frac{\mathrm{d} v_{1}}{\mathrm{~d} t}+\frac{\mathrm{d} v_{2}}{\mathrm{~d} t}\right)=-v_{1}\left(v_{1}-v_{2}\right)=\frac{\beta}{1-\beta} v_{1}^{2}=\beta(1-\beta) v_{2}^{2}
$$

The expressions with $\beta$ are for later use.

Frictional Acceleration With Holdup. The combined model (roughly Eqs. (2) and (7)) is derived in the Appendix. In terms of the slug front velocity $v_{1}$, slug length $L$, and slug front position $x_{1}$, the governing equations read

$$
\begin{aligned}
\frac{1-\frac{1}{2} \beta}{1-\beta} L(t) \frac{\mathrm{d} v_{1}}{\mathrm{~d} t}(t)= & \frac{\beta}{1-\beta} v_{1}^{2}(t)+\frac{P_{2}(t)-P_{1}(t)}{\rho} \\
& +g \sin \theta L(t)-\frac{f}{2 D} \frac{1-\beta+\frac{1}{3} \beta^{2}}{(1-\beta)^{2}} L(t) v_{1}^{2}(t)
\end{aligned}
$$

$$
\begin{gathered}
\frac{\mathrm{d} L}{\mathrm{~d} t}(t)=-\frac{\beta}{1-\beta} v_{1}(t) \\
\frac{\mathrm{d} x_{1}}{\mathrm{~d} t}(t)=v_{1}(t)
\end{gathered}
$$

The holdup coefficient $\beta$ is assumed to be constant and defined such that the cross-sectional area of the liquid layer that is left behind is $\beta A$ (Fig. 2). The holdup coefficient determines the slug's life time and travel length. Equation $(9 a)$ is consistent with Eq. (2), where $\beta$ is zero and consequently $L$ is constant. Equation ( $9 a$ ) is consistent with Eq. (7) (up to first-order in $\beta$ and depending on the choices for $v$ and $\mathrm{d} v / \mathrm{d} t$, see the Appendix). Equations $(9 a)$ and $(9 b)$ can be combined into one strongly nonlinear secondorder ordinary differential equation (ODE) for $L$, but there is no obvious advantage when the equations are solved numerically. Equation $(9 a)$ is an improvement with respect to previous work by the authors $[1,2]$, in the sense that the factors containing $\beta$ make the inertia and friction terms more accurate. The first term on the right (the holdup term) lacks the factor two obtained initially by one of the authors [7], who had assumed that the velocity in the entire control volume between $x_{1}$ and $x_{2}$ in Fig. 2 was equal to the front velocity of the slug. Dealing with an accelerating control volume that loses mass is tricky and a proper interpretation of the involved slug dynamics definitely helps understanding the mathematical model and its peculiarities.

Integration of Eq. $(9 b)$ leads to

$$
\frac{L(t)}{L\left(t_{0}\right)}=1-\frac{\beta}{1-\beta} \frac{x_{1}(t)-x_{1}\left(t_{0}\right)}{x_{1}\left(t_{0}\right)-x_{2}\left(t_{0}\right)}=1-\frac{\beta}{1-\beta} \frac{L_{\text {pipe }}}{L_{0}}
$$

where $L(t)=x_{1}(t)-x_{2}(t), L_{0}:=L\left(t_{0}\right)$, and $L_{\text {pipe }}=x_{1}(t)-x_{1}\left(t_{0}\right)$ is the distance traveled by the slug front. This formula is different from the one given in Ref. [1], where the slightly larger distance traveled by the slug tail was considered.

An analytical solution is derived as follows. Take a constant pressure difference $P_{2}-P_{1}>0, \beta>0, f=0$, and $\theta=0$. Use Eq. $(9 b)$ to eliminate $v_{1}$ in Eq. $(9 a)$. The result is

$$
L \frac{\mathrm{d}^{2} L}{\mathrm{~d} t^{2}}=-\frac{1-\beta}{1-\frac{1}{2} \beta}\left(\frac{\mathrm{d} L}{\mathrm{~d} t}\right)^{2}-\frac{\beta}{1-\frac{1}{2} \beta} \frac{P_{2}-P_{1}}{\rho}
$$

Consider $\mathrm{d} L / \mathrm{d} t$ as a function of slug length $L$. That is, $\mathrm{d} L / \mathrm{d} t:=w(L)<0$, so that

$$
\frac{\mathrm{d}^{2} L}{\mathrm{~d} t^{2}}=\frac{\mathrm{d} w}{\mathrm{~d} L} \frac{\mathrm{d} L}{\mathrm{~d} t}=w \frac{\mathrm{d} w}{\mathrm{~d} L}=\frac{1}{2} \frac{\mathrm{d} w^{2}}{\mathrm{~d} L}
$$

Equation (11) then becomes a linear ODE for $w^{2}$

$$
\frac{\mathrm{d} w^{2}}{\mathrm{~d} L}+\frac{2}{L} \frac{1-\beta}{1-\frac{1}{2} \beta} w^{2}=-\frac{2}{L} \frac{\beta}{1-\frac{1}{2} \beta} \frac{P_{2}-P_{1}}{\rho}
$$

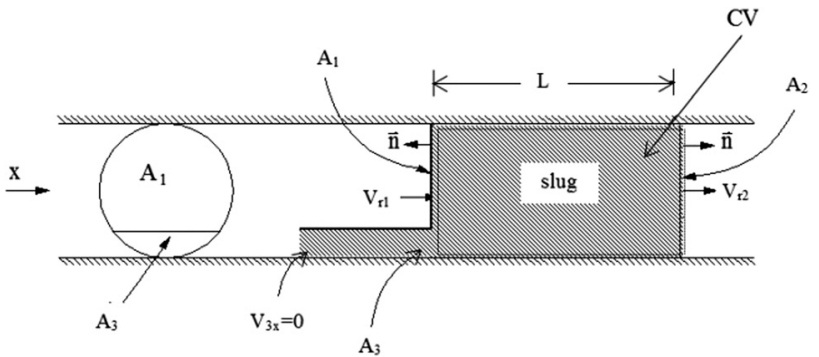

Fig. 2 Slug motion with mass shedding (definition of symbols in Ref. [2]) 
The solution for the initial condition $v_{1}\left(t_{0}\right)=0$ or $w\left(L_{0}\right)=0$ is

$$
w^{2}=\left(\left(\frac{L_{0}}{L}\right)^{\alpha}-1\right) \frac{\beta}{1-\beta} \frac{P_{2}-P_{1}}{\rho} \text { with } \alpha:=2 \frac{1-\beta}{1-\frac{1}{2} \beta}
$$

Using Eqs. (9b) and (10), the solution for $v_{1}$ as a function of $L_{\text {pipe }}$ is

$$
v_{1}=\sqrt{\frac{1}{\left(1-\frac{\beta}{1-\beta}\left(\frac{L_{\mathrm{pipe}}}{L_{0}}\right)^{\alpha}\right)}-1} \sqrt{\frac{1-\beta}{\beta} \frac{P_{2}-P_{1}}{\rho}}
$$

The corresponding formula for $f>0$ and $\theta=0$ is in terms of incomplete gamma functions

$$
\begin{gathered}
v_{1}=\mathrm{e}^{f^{*} L} \sqrt{\frac{\Gamma\left(\alpha, 2 L f^{*}\right)}{\left(2 L f^{*}\right)^{\alpha}}-\frac{\Gamma\left(\alpha, 2 L_{0} f^{*}\right)}{\left(2 L_{0} f^{*}\right)^{\alpha}}\left(\frac{L_{0}}{L}\right)^{\alpha}} \\
\sqrt{2 \frac{(1-\beta)^{2}}{\beta\left(1-\frac{1}{2} \beta\right)} \frac{P_{2}-P_{1}}{\rho}}
\end{gathered}
$$

where $f^{*}:=(f / 2 D)\left(1-\beta+\beta^{2} / 3\right) /\left(\beta-\beta^{2} / 2\right)$ and $L=L_{0}$ $-\beta /(1-\beta) L_{\text {pipe }}$ (Eq. (10)). See the Appendix for the full derivation. If $2 L_{0} f^{*}>37$ (for $1.7 \leq \alpha \leq 2$ ), the incomplete gamma functions are of the order of $10^{-15}$ and therefore replaced by the leading term of their asymptotic expansions $\Gamma(\alpha, \lambda)=\lambda^{\alpha-1} \mathrm{e}^{-\lambda}(1+(\alpha-1) / \lambda+\ldots)$, so that Eq. (16) becomes

$$
v_{1}=\sqrt{1-\left(\frac{L_{0}}{L}\right)^{\alpha-1} \mathrm{e}^{-2\left(L_{0}-L\right) f^{*}}} \sqrt{\frac{(1-\beta)^{2}}{\beta\left(1-\frac{1}{2} \beta\right)} \frac{P_{2}-P_{1}}{\rho L f^{*}}}
$$

In dimensionless form this formula reads

$$
\frac{v_{1}}{v_{\infty}}=\frac{1-\beta}{\sqrt{1-\beta+\frac{1}{3} \beta^{2}}} \sqrt{\frac{L_{0}}{L}-\left(\frac{L_{0}}{L}\right)^{\alpha} \mathrm{e}^{-2\left(L_{0}-L\right) f^{*}}}
$$

where $v_{\infty}=\sqrt{C_{1} / C_{2}}$ is the final $(t=\infty)$ velocity of the slug when there is no holdup $(\beta=0)$. The general case $f>0$ and $\theta \neq 0$ is presented in the Appendix.

After Arrival at the Elbow. The theory presented so far is used to predict the velocity and length of the slug at the instant it arrives at an obstacle, such as an elbow, located at a distance $L_{\text {pipe }}$

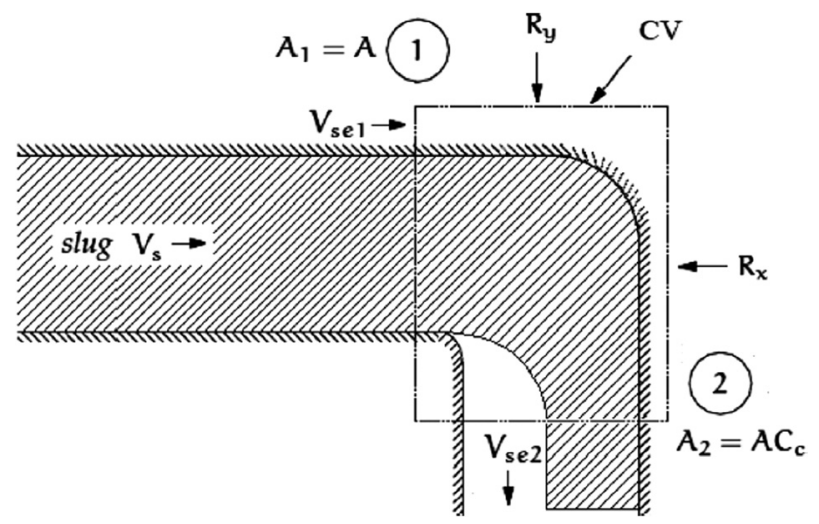

Fig. 3 Flow separation at elbow in Ref. [1] downstream. In Ref. [1], it was demonstrated that flow separation occurs at the elbow (Fig. 3), and that this can be modeled by switching on an additional "resistance" in Eq. $(9 a)$. Given that the time of arrival of the slug front at the elbow's entrance and exit is $t_{1}$ and $t_{2}$, respectively, and $L_{\mathrm{e}}$ is a representative length of the elbow, then the governing equation for a straight pipe terminated by an open elbow $\left(P_{1}(t) \equiv 0\right)$ is obtained as Eq. $(9 a)$ with a modified driving pressure, i.e.,

$$
\begin{aligned}
P_{2}(t)-P_{1}(t)= & P_{2}(t)-\left(\frac{1}{C_{\mathrm{c}}^{2}}-1+K_{\mathrm{e}}\right) \\
& \times \frac{\left(t-t_{1}\right) \mathrm{H}\left(t-t_{1}\right)-\left(t-t_{2}\right) \mathrm{H}\left(t-t_{2}\right)}{t_{2}-t_{1}} \frac{\rho v_{1}^{2}(t)}{2}
\end{aligned}
$$

where $C_{\mathrm{c}}$ is the flow contraction coefficient at the elbow, $K_{\mathrm{e}}$ is the elbow's minor loss coefficient, and $\mathrm{H}$ is the Heaviside step function. The build-up of the additional resistance is assumed to take place linear in time, where the time interval $t_{2}-t_{1}$ is approximated by $\left(L_{\mathrm{e}}+L_{\text {front }}\left(t_{1}\right)\right) / v_{1}$, where $L_{\text {front }}$ is the axial length of a wedge-shaped slug-front $\left(L_{\text {front }}\left(t_{0}\right)\right.$ in Fig. $\left.4(b)\right)$. This front will steepen during traveling. The fraction containing the Heaviside functions is replaced by unity for instantaneous impacts $\left(t_{2}=t_{1}\right)$ [1], in which case closed-form solutions can be derived (not presented herein).

\section{Numerical Integration}

Numerical integration is required when the pressure difference $P_{2}-P_{1}$ is not constant but given by measured or calculated (using gas dynamics) values. It is also required when the pipe slope is not constant, or the slug front is wedge-shaped and hitting the elbow gradually $\left(t_{2} \neq t_{1}\right.$ in Eq. (18)). The governing equations (9) can be casted in the standard form

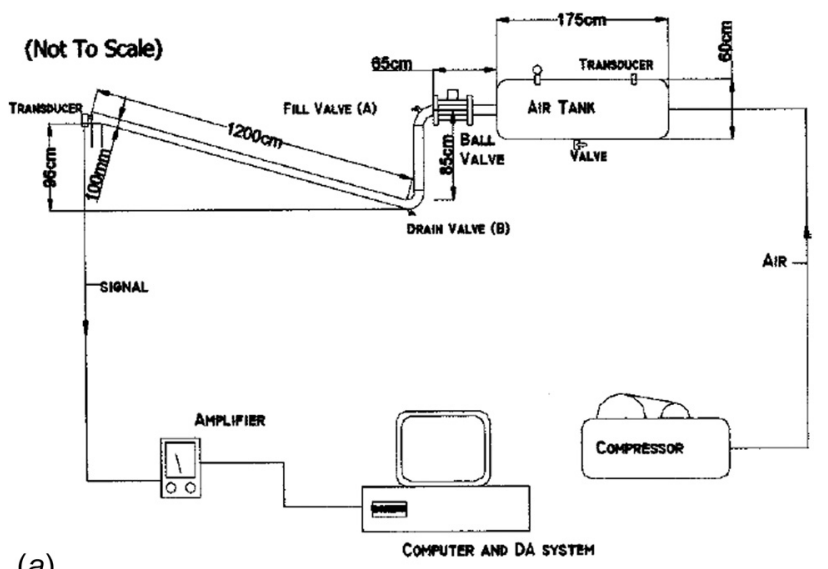

(a)

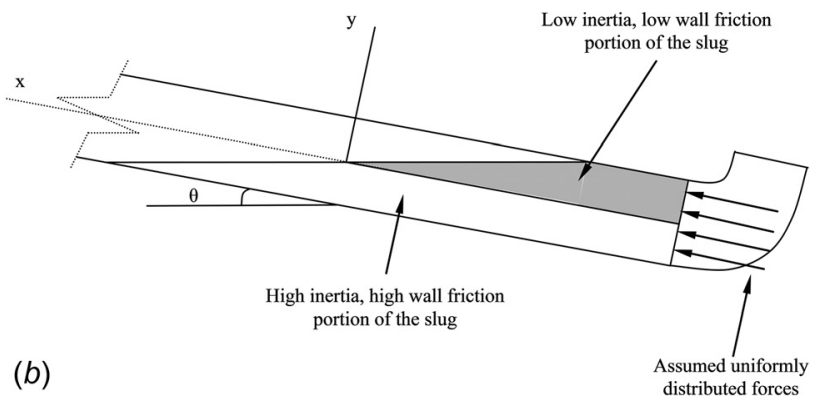

Fig. 4 Schematic: (a) experimental setup and (b) initial slug [3] 


$$
\frac{\mathrm{d} \boldsymbol{y}}{\mathrm{d} t}=\boldsymbol{f}(t, \boldsymbol{y}), \text { with } \boldsymbol{y}:=\left(\begin{array}{c}
v_{1} \\
L \\
x_{1}
\end{array}\right)
$$

The local stability of the solutions is investigated through the Jacobian matrix $\boldsymbol{J}$ of $\boldsymbol{f}$ with respect to $\boldsymbol{y}$. Any suitable numerical integration scheme can be used to solve Eq. (19). The explicit Euler method will do the job if the time step $\Delta t$ is taken sufficiently small; the modulus of the (complex valued) eigenvalues of $\boldsymbol{I}+\Delta t \boldsymbol{J}$ must then be smaller than $1[8]$.

\section{Laboratory Experiment}

The experimental setup described in Ref. [3] is used as test problem. It can be regarded as an air gun carrying a water bullet. The key part is a $12 \mathrm{~m}$ long inclined $(\theta=-0.08 \mathrm{rad}=-4.6 \mathrm{deg})$ pipe of $0.1 \mathrm{~m}$ diameter leading upwards to an open 85.4 deg miter bend (i.e., 94.6 deg turning angle) with an $0.4 \mathrm{~m}$ long vertical leg downward, see Fig. 4(a). A slug of water is at rest in the lower elbow (see Fig. 4(b)), before it starts to accelerate due to a suddenly applied pressure provided by compressed air from an $0.5 \mathrm{~m}^{3}$ tank (Fig. 5(a)). Initial slug lengths were $L_{0}=3,4,5$, or $6 \mathrm{~m}$ undergoing driving pressure differences of $\Delta P=2,3,4$, or 5 bar. It is noted that the driving pressure in the laboratory experiments was not constant but decreased (gradually) by an estimated $10 \%$. The slug impact pressure was measured at one location, namely, the intersection of the pipe central axis and the miter bend (Fig. 5(b)).

\section{Parameter Variation Study}

Here, we ignore the pipe inclination, the wedge-shaped slug front and the upper elbow. The pipe diameter is taken ten times

(a)
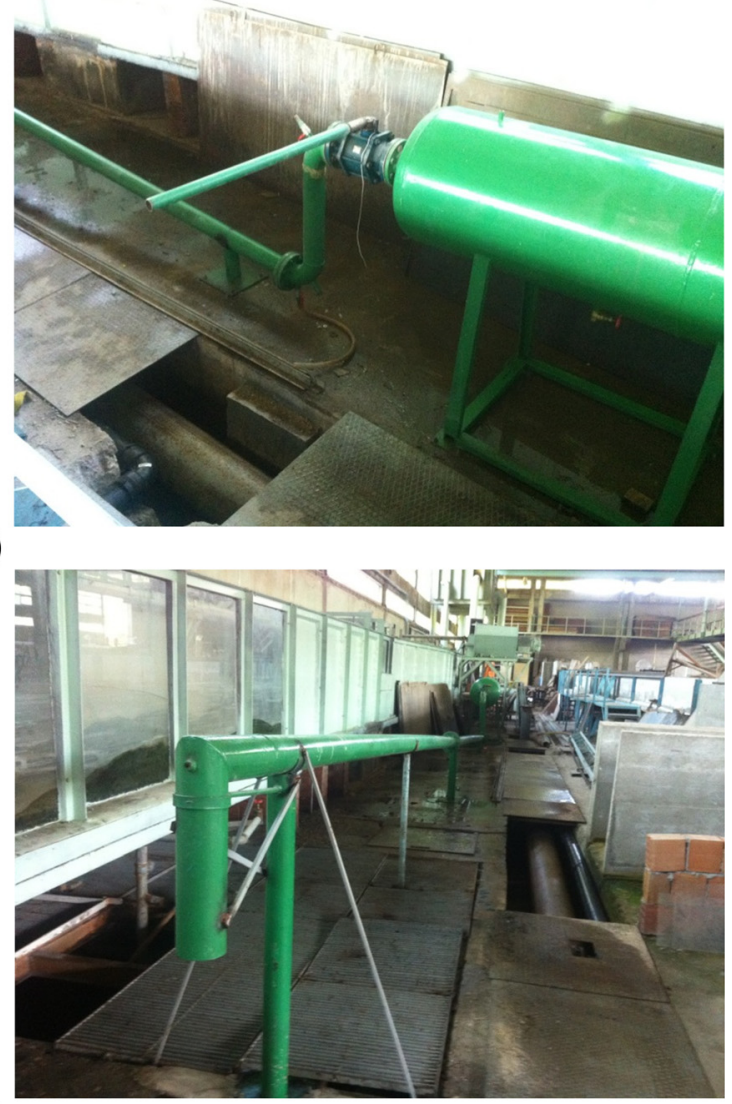

(b)

Fig. 5 Test rig: (a) lower elbow and tank with compressed air and $(b)$ upper elbow smaller $(D=0.01 \mathrm{~m})$ to enhance the effect of friction. The slugs are allowed to travel as far as they can, until they vanish, say at $L=D$. This normally is the lower limit of $1 \mathrm{D}$ theory, where things are long and slender, and it certainly is the point where the planar front and tail have smeared out so much that the liquid slug does not occupy the full pipe cross section anymore. The travel length $L_{\mathrm{v}}$ up to this point is found from Eq. (10) by taking $L(t)=D$

$$
L_{\mathrm{v}}=\frac{1-\beta}{\beta}\left(L_{0}-D\right)
$$

For $\beta=0.05,0.1,0.2$, and 0.3 this gives travel distances of 19,9 , 4 , and 2.3 times the initial slug length (minus $D$ ).

Case 1 concerns a slug of initial length $3 \mathrm{~m}$ and mass $24 \mathrm{~kg}$ driven by a pressure difference of 5 bar. In case 2 , these values are $5 \mathrm{~m}, 40 \mathrm{~kg}$, and $2 \mathrm{bar}$. The input values for the simulations are: pipe diameter $D=0.01 \mathrm{~m}$, friction factor $f=0.016$, mass density $\rho=1000 \mathrm{~kg} / \mathrm{m}^{3}$, initial slug length $L_{0}=3$ (5) m, driving pressure difference $\Delta P=5$ (2) bar, inclination angle $\theta=0$, and holdup coefficient $\beta=0,0.05,0.1,0.15$, or 0.2 . The slug is at rest before it starts to accelerate at $t=0$ due to the sudden pressure difference $\Delta P$. The calculated velocity and acceleration histories as presented in Figs. 6 and 7 are discussed below.

The influence of the holdup (coefficient) is examined through the slug velocities in Fig. 6. Holdup slightly decreases the fast initial acceleration and largely increases the slow final acceleration. The five different lines meet at nearly the same (inflection) point. Because the governing equations are strongly nonlinear, not much can be said about this most interesting point. The inflection point marks the division of two regimes: one of large acceleration before it, and one of moderate acceleration (due to holdup) after

(a)

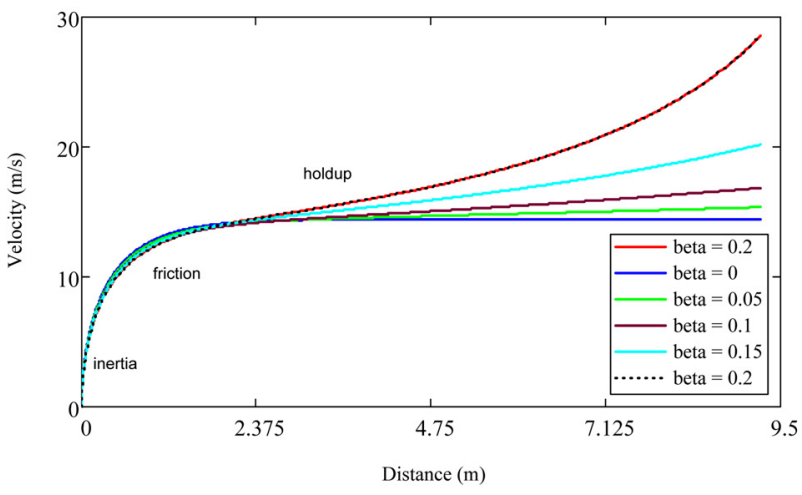

(b)

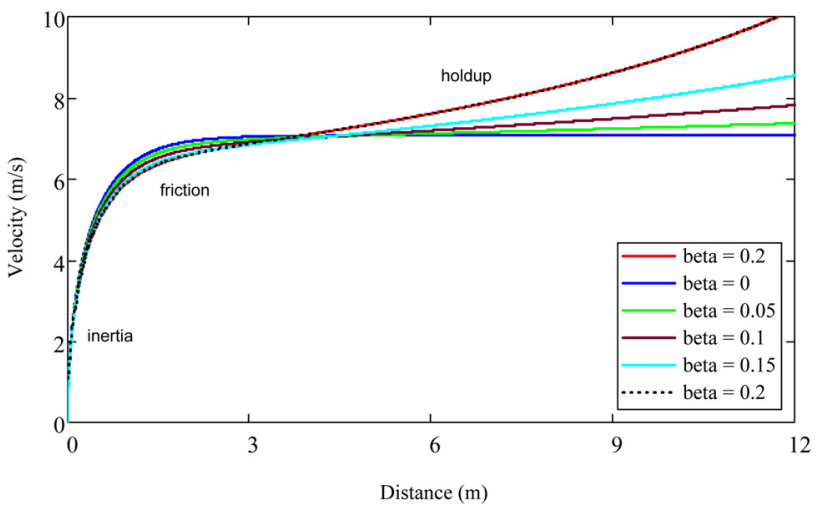

Fig. 6 Velocity $\left(v_{1}\right)$ as function of distance $\left(x_{1}\right)$ for different values of $\beta$ : (a) case 1 and $(b)$ case 2 . Solid lines: analytical solutions (Eqs. (5) for $\beta=0,(16)$, and (17)); broken line (coinciding with solid line for $\beta=0.2$ ): numerical solution. 
(a)

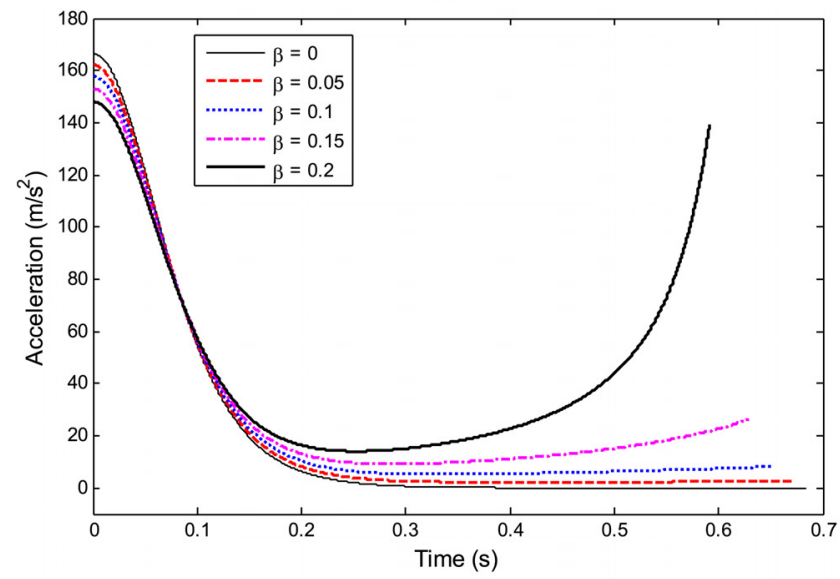

(b)

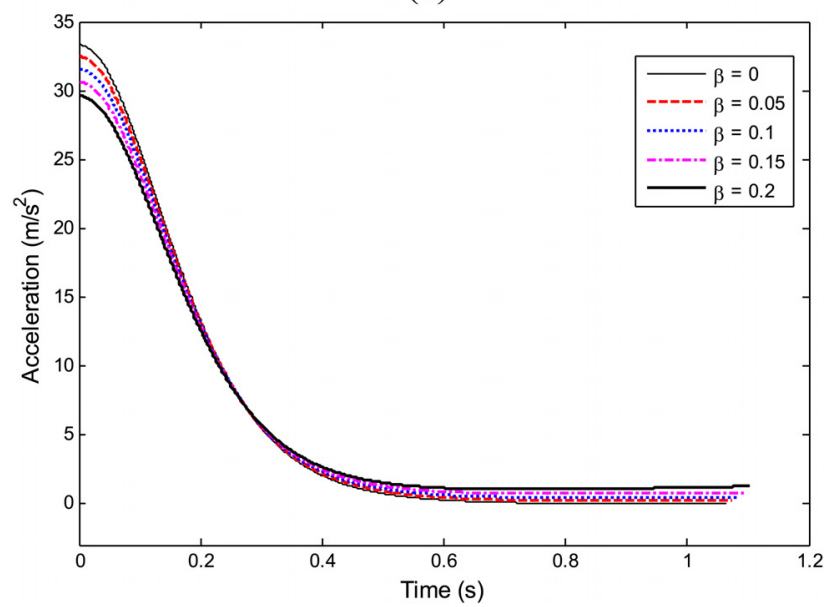

Fig. 7 Acceleration history for different values of $\beta$ : (a) case 1 and $(b)$ case 2

it. Without holdup the flow becomes steady. The value of the velocity at the inflection point is more or less independent of the holdup and only depends on friction and inertia. This velocity is therefore very close to $v_{\infty}$ defined in Eq. (3). Beyond the inflection point, holdup becomes important because the mass lost per unit time increases with velocity (Eq. (A1)) and becomes large compared to the decreasing slug mass, see Eqs. (6) and (8).

The corresponding acceleration histories are shown in Fig. 7. At $t=0, v_{1}=0$, so that the initial acceleration determined by Eq. $(9 a)$ is

$$
\frac{\mathrm{d} v_{1}}{\mathrm{~d} t}(0)=\frac{1-\beta}{1-\frac{1}{2} \beta} \frac{\Delta P}{\rho L_{0}}
$$

where the factor $(1-\beta) /(1-\beta / 2)$ is 1 for $\beta=0$ and $8 / 9$ for $\beta=0.2$. The value $8 / 9$ accounts for the nonuniform velocity distribution (because $v_{1} \neq v_{2}$ ).

\section{Validation}

In the simulation of the laboratory experiment [3], the upper elbow is taken into account with a length of say $L_{\mathrm{e}}=D$. When the wedge-shaped slug front (Fig. $4 b$ ) reaches the elbow at $t=t_{1}$, the slug starts to experience an additional resistance according to Eq. (18). The estimated distance traveled by the slug front before it arrives at the elbow is $9.5 \mathrm{~m}$ (and $7.4 \mathrm{~m}$ ) for case 1 (and case 2). The input values for the simulations are: pipe diameter $D=0.1 \mathrm{~m}$,

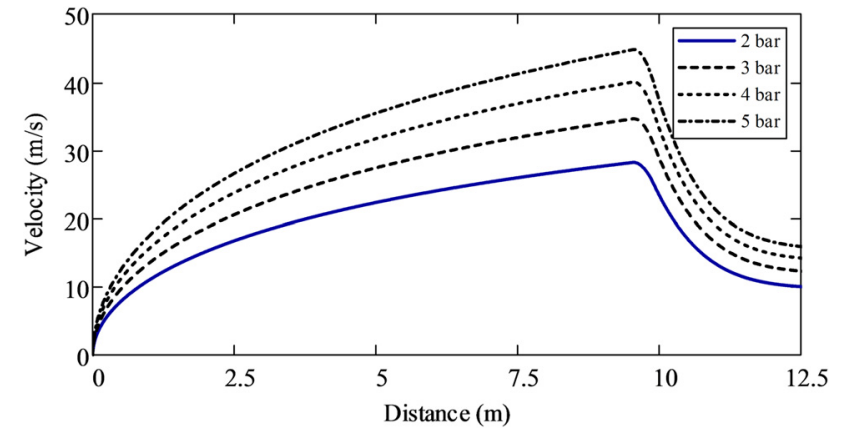

Fig. 8 Velocity history of the front of a $24 \mathrm{~kg}$ slug $\left(L_{0}=3.0 \mathrm{~m}\right)$. Prediction by $1 \mathrm{D}$ model.

(a)

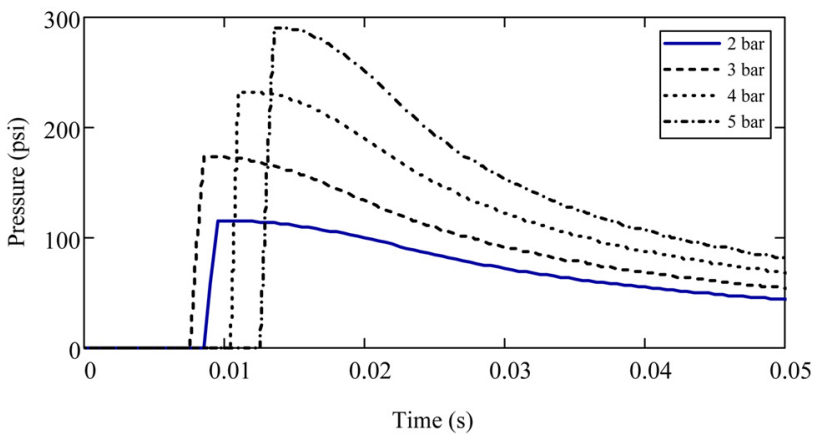

(b)

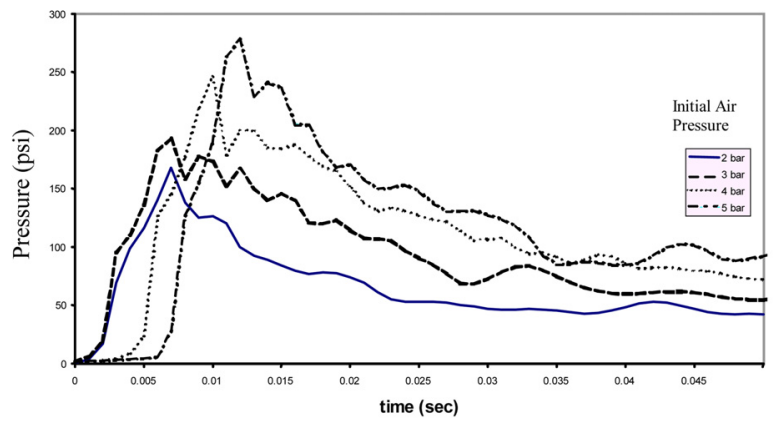

Fig. 9 Pressure history at the elbow for a $24 \mathrm{~kg}$ slug $\left(L_{0}=3.0 \mathrm{~m}\right)(100 \mathrm{psi} \approx 7 \mathrm{bar})$ : (a) prediction by $1 \mathrm{D}$ model and $(b)$ measurement [3]

traveled distance $L_{\text {pipe }}=9.5(7.4) \mathrm{m}$, elbow length $L_{\mathrm{e}}=D$, elbow loss coefficient $K_{\mathrm{e}}=0.9$, flow contraction coefficient $C_{\mathrm{c}}=0.50$ [9,10], slug front length $L_{\text {front }}\left(t_{1}\right)=3 D$, friction factor $f=0.016$, inclination angle $\theta=-0.08 \mathrm{rad}$, mass density $\rho=1000 \mathrm{~kg} / \mathrm{m}^{3}$,

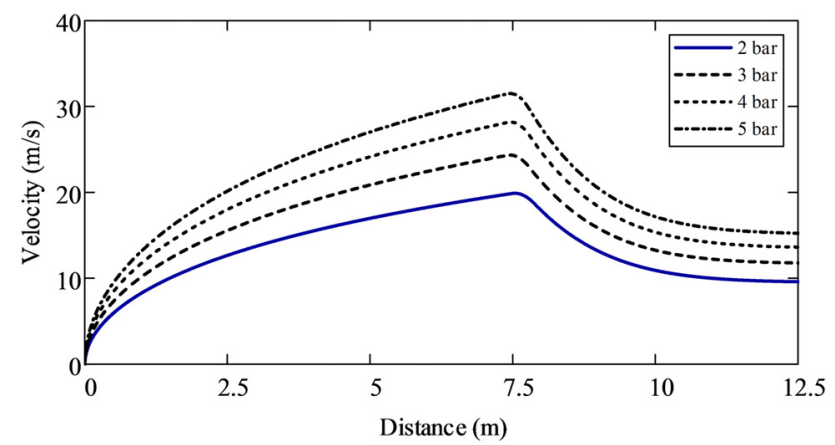

Fig. 10 Velocity history of the front of a $40 \mathrm{~kg}$ slug $\left(L_{0}=5.1 \mathrm{~m}\right)$. Prediction by 1D model. 
(a)

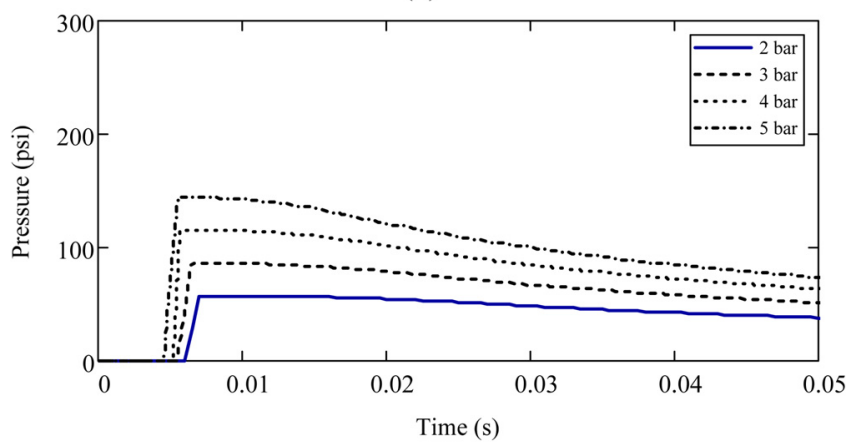

(b)

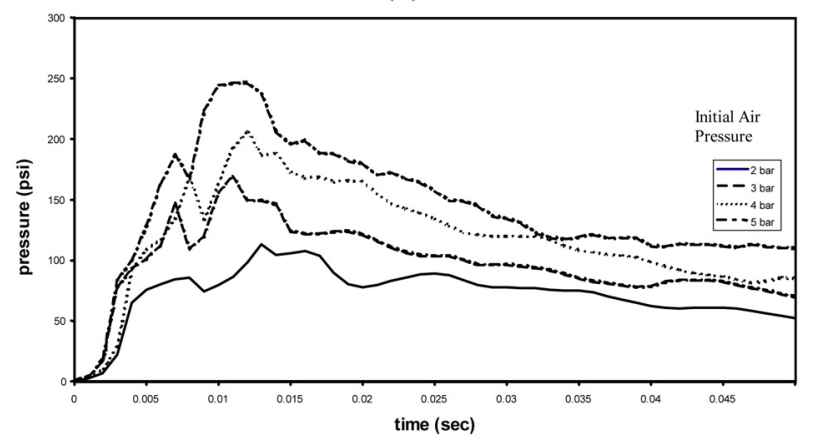

Fig. 11 Pressure history at the elbow for a $40 \mathrm{~kg}$ slug $\left(L_{0}=5.1 \mathrm{~m}\right)(100 \mathrm{psi} \approx 7$ bar $)$ : $(a)$ prediction by $1 \mathrm{D}$ model and $(b)$ measurement [3]

initial slug length $L_{0}=3.0(5.1) \mathrm{m}$, driving pressure difference $\Delta P=2,3,4$ or 5 bar, and an estimated holdup coefficient $\beta=0.05$ (0.1). The influence of $\beta$ is small, because the inflection point (Fig. 6) is not reached (Figs. 8 and 10) in the relatively short test pipe $\left(L_{\text {pipe }} / L_{0}=3.2(1.5)\right)$. The theoretical length of existence $L_{\mathrm{v}}$ (Eq. (20)) is $57 \mathrm{~m}(46 \mathrm{~m})$ for the $3.0 \mathrm{~m}(5.1 \mathrm{~m})$ slug. The influence of gravity $(g \sin \theta)$ is small too; it reduces the driving force by $1.2 \%$ to $0.5 \%$ (2\% to $0.8 \%$ ) for pressures $P_{2}$ ranging from 2 bar to 5 bar and $L_{0}=3 \mathrm{~m}(5 \mathrm{~m})$.

For the highest pressure of 5 bar driving the $24 \mathrm{~kg}\left(L_{0}=3.0 \mathrm{~m}\right)$ slug, the slug front hits the elbow after $t_{1}=0.37 \mathrm{~s}$ with a mass of $20 \mathrm{~kg}(L=2.5 \mathrm{~m})$ and a velocity $v_{1}$ of $45 \mathrm{~m} / \mathrm{s}$, see Fig. 8 . This gives an impact pressure of 20 bar. The pressure within the elbow is strongly nonuniform, both along and perpendicular to streamlines [11]. Here, we take the conservative estimate $P_{\mathrm{e}}=\rho v_{1}^{2}$. The flow contraction at the elbow acts as a resistance slowing down the slug motion. Calculated (shifted in time) and measured pressures are shown in Fig. 9. The observed magnitudes and shapes agree well in view of the many uncertainties in mathematical model and physical experiment.

For the highest pressure of 5 bar driving the $40 \mathrm{~kg}\left(L_{0}=5.1 \mathrm{~m}\right)$ slug, the slug front hits the elbow after $t_{1}=0.425 \mathrm{~s}$ with a mass of $34 \mathrm{~kg}(L=4.3 \mathrm{~m})$ and a velocity $v_{1}$ of $31.5 \mathrm{~m} / \mathrm{s}$, see Fig. 10 . This gives an impact pressure of 10 bar. Calculated (shifted in time) and measured pressures are shown in Fig. 11. The trends agree well in view of the many uncertainties, but the magnitudes are systematically under-predicted (60\% for the 5 bar case).

\section{Conclusion}

A refined 1D model for slug propagation has been derived and analytical solutions are given for the case that the driving pressure and pipe slope are constant. Analytical solutions for limit cases ( $\beta=0$ and $f=0)$ provide useful guidance. The model was able to correctly predict trends and magnitudes in measured data, although for long slugs the impact pressures were systematically underestimated.

\section{Acknowledgment}

This paper is an amended version of Paper No. 28693 presented at the ASME PVP2014 conference held in Anaheim, CA. The second author is grateful for the support by the National Natural Science Foundation of China (No. 51478305) and SKL of HESS (HESS-1408). The authors thank the anonymous reviewers for their good suggestions.

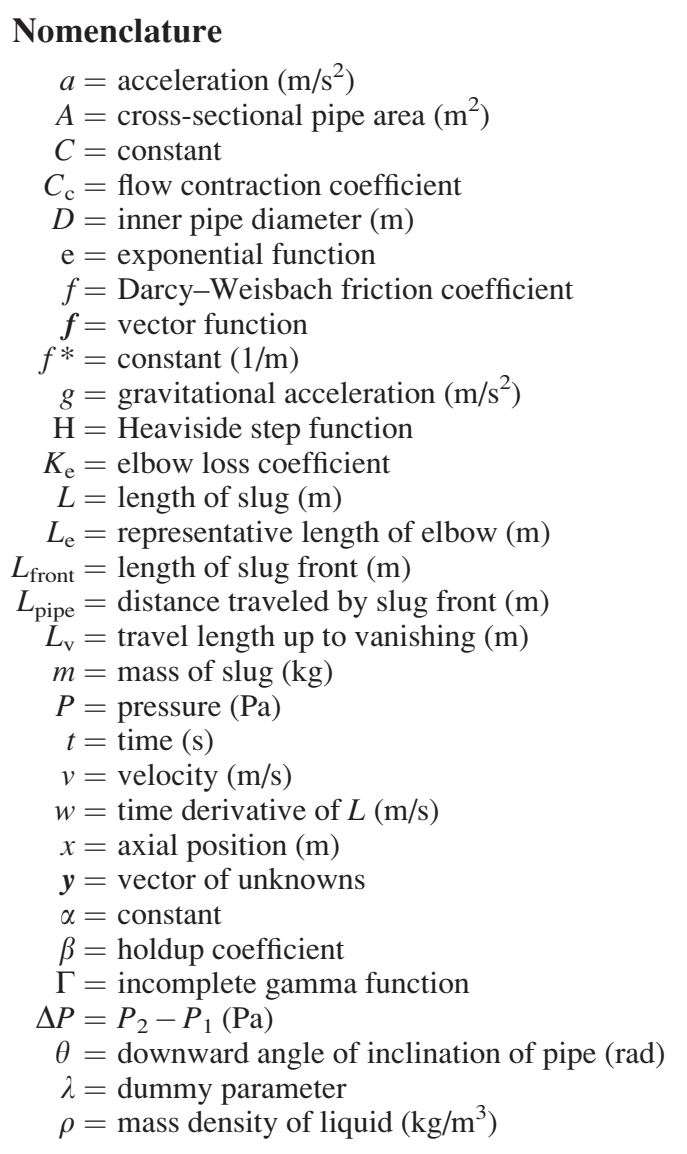

\section{Subscripts}

$$
\begin{aligned}
\mathrm{c} & =\text { contraction } \\
\mathrm{e} & =\text { elbow } \\
\mathrm{hu} & =\text { holdup } \\
\mathrm{v} & =\text { vanish } \\
0 & =\text { initial value; constant value } \\
1 & =\text { slug front; front arrival time at elbow; index } \\
2 & =\text { slug tail; front exit time from elbow; index } \\
\infty & =\text { final value }
\end{aligned}
$$

\section{Appendix: Derivation of Governing Equations and Analytical Solutions}

The moving liquid slug loses mass at its tail at a rate proportional to the distance traveled and leaves behind a liquid layerthe holdup-occupying a constant fraction $\beta A$ of the pipe cross-sectional area $A$. The pipe has a downward angle of inclination $\theta$.

Conservation of Mass. The moving mass balance is (Fig. 1)

$$
\frac{\mathrm{d}}{\mathrm{d} t} \int_{x_{2}(t)}^{x_{1}(t)} \rho A \mathrm{~d} x=-\rho A \beta \frac{\mathrm{d} x_{2}}{\mathrm{~d} t}(t)
$$


which directly leads to

$$
\frac{\mathrm{d} x_{1}}{\mathrm{~d} t}(t)-\frac{\mathrm{d} x_{2}}{\mathrm{~d} t}(t)=-\beta \frac{\mathrm{d} x_{2}}{\mathrm{~d} t}(t)
$$

or

$$
v_{1}(t)=(1-\beta) v_{2}(t)
$$

Integration gives

$$
L(t)-L\left(t_{0}\right)=-\beta\left(x_{2}(t)-x_{2}\left(t_{0}\right)\right)
$$

with $L(t)=x_{1}(t)-x_{2}(t)$.

In terms of $v_{1}$ and $L$, the governing equation is

$$
\frac{\mathrm{d} L}{\mathrm{~d} t}(t)=-\frac{\beta}{1-\beta} v_{1}(t)
$$

This is exactly the same as in previous work $[1,2]$.

Conservation of Momentum. The momentum balance (that is consistent with the moving mass balance) is

$$
\begin{aligned}
& \frac{\mathrm{d}}{\mathrm{d} t} \int_{x_{2}(t)}^{x_{1}(t)} \rho A v(x, t) \mathrm{d} x=-\rho A \beta\left(v_{2}(t)-v_{\mathrm{hu}}(t)\right) \frac{\mathrm{d} x_{2}}{\mathrm{~d} t}(t) \\
& \quad+\left(P_{2}(t)-P_{1}(t)\right) A+g \int_{x_{2}(t)}^{x_{1}(t)} \rho A \sin \theta \mathrm{d} x-\frac{f}{2 D} \int_{x_{2}(t)}^{x_{1}(t)} \rho A v^{2}(x, t) \mathrm{d} x
\end{aligned}
$$

where $v_{\text {hu }}(t)$ is the velocity of the holdup directly behind the slug tail. For the sake of simplicity, and because it is an unknown factor, $v_{\text {hu }}(t)$ is taken zero herein, i.e., the holdup sticks to the pipe wall. Applying Leibniz's rule results in (with $v_{\text {hu }}(t) \equiv 0$ )

$$
\begin{aligned}
\left.\left.v\left(x_{1}(t), t\right)\right) \frac{\mathrm{d} x_{1}}{\mathrm{~d} t}(t)-v\left(x_{2}(t), t\right)\right) \frac{\mathrm{d} x_{2}}{\mathrm{~d} t}(t)+\int_{x_{2}(t)}^{x_{1}(t)} \frac{\partial v}{\partial t}(x, t) \mathrm{d} x \\
=-\beta v_{2}^{2}(t)+\frac{P_{2}(t)-P_{1}(t)}{\rho}+g \sin \theta\left(x_{2}(t)-x_{1}(t)\right) \\
\quad-\frac{f}{2 D} \int_{x_{2}(t)}^{x_{1}(t)} v^{2}(x, t) \mathrm{d} x
\end{aligned}
$$

Rearranging gives

$$
\begin{aligned}
& \int_{x_{2}(t)}^{x_{1}(t)} \frac{\partial v}{\partial t}(x, t) \mathrm{d} x-\frac{P_{2}(t)-P_{1}(t)}{\rho}-g \sin \theta L(t) \\
& =-v_{1}^{2}(t)+(1-\beta) v_{2}^{2}(t)-\frac{f}{2 D} \int_{x_{2}(t)}^{x_{1}(t)} v^{2}(x, t) \mathrm{d} x \\
& =\beta v_{1}(t) v_{2}(t)-\frac{f}{2 D} \int_{x_{2}(t)}^{x_{1}(t)} v^{2}(x, t) \mathrm{d} x \\
& =\frac{\beta}{1-\beta} v_{1}^{2}(t)-\frac{f}{2 D} \int_{x_{2}(t)}^{x_{1}(t)} v^{2}(x, t) \mathrm{d} x \\
& =\beta(1-\beta) v_{2}^{2}(t)-\frac{f}{2 D} \int_{x_{2}(t)}^{x_{1}(t)} v^{2}(x, t) \mathrm{d} x
\end{aligned}
$$

The two integrals in Eq. (A7) are approximated. Assuming that the velocity increases linearly from $v_{1}$ at $x_{1}$ to $v_{2}$ at $x_{2}$ yields

$$
\begin{aligned}
\int_{x_{2}(t)}^{x_{1}(t)} \frac{\partial v}{\partial t}(x, t) \mathrm{d} x & \approx \frac{1}{2}\left(\frac{\partial v}{\partial t}\left(x_{1}(t), t\right)+\frac{\partial v}{\partial t}\left(x_{2}(t), t\right)\right)\left(x_{1}(t)-x_{2}(t)\right) \\
& =\frac{1}{2}\left(\frac{\mathrm{d} v_{1}}{\mathrm{~d} t}(t)+\frac{\mathrm{d} v_{2}}{\mathrm{~d} t}(t)\right)\left(x_{1}(t)-x_{2}(t)\right) \\
& =\frac{1-\frac{1}{2} \beta}{1-\beta} L(t) \frac{\mathrm{d} v_{1}}{\mathrm{~d} t}(t)=\left(1-\frac{1}{2} \beta\right) L(t) \frac{\mathrm{d} v_{2}}{\mathrm{~d} t}(t)
\end{aligned}
$$

$$
\begin{aligned}
\int_{x_{2}(t)}^{x_{1}(t)} v^{2}(x, t) \mathrm{d} x & \approx \frac{1}{3}\left(v^{2}\left(x_{1}(t), t\right)\right. \\
& \left.+v\left(x_{1}(t), t\right) v\left(x_{2}(t), t\right)+v^{2}\left(x_{2}(t), t\right)\right)\left(x_{1}(t)-x_{2}(t)\right) \\
& =\frac{1}{3}\left(v_{1}^{2}(t)+v_{1}(t) v_{2}(t)+v_{2}^{2}(t)\right)\left(x_{1}(t)-x_{2}(t)\right) \\
& =\frac{1-\beta+\frac{1}{3} \beta^{2}}{(1-\beta)^{2}} L(t) v_{1}^{2}(t) \\
& =\left(1-\beta+\frac{1}{3} \beta^{2}\right) L(t) v_{2}^{2}(t)
\end{aligned}
$$

In terms of $v_{1}$ and $L$, the governing equation is

$$
\begin{aligned}
\frac{1-\frac{1}{2} \beta}{1-\beta} L(t) \frac{\mathrm{d} v_{1}}{\mathrm{~d} t}(t) & =\frac{\beta}{1-\beta} v_{1}^{2}(t)+\frac{P_{2}(t)-P_{1}(t)}{\rho} \\
& +g \sin \theta L(t)-\frac{f}{2 D} \frac{1-\beta+\frac{1}{3} \beta^{2}}{(1-\beta)^{2}} L(t) v_{1}^{2}(t)
\end{aligned}
$$

This is different from previous work [1,2]; there are first-order (in $\beta$ ) corrections to both the inertia and friction term, and a factor two in the holdup term is absent here (conform Eq. (8)).

A minor improvement would be to make the friction factor $f$ dependent on $V$. However, for accelerating flows an unsteady friction model is strongly advised [12-15]. Starting from rest, theoretically the flow is initially laminar.

Analytical Solution. An analytical solution can be derived for $v_{1}$ when the pressure difference $P_{2}-P_{1}>0$ is constant, $\theta$ is constant and $0<\beta<1$. Equation (A4) is used to eliminate $v_{1}$ from Eq. (A10), so that

$$
\begin{aligned}
L \frac{\mathrm{d}^{2} L}{\mathrm{~d} t^{2}}= & -\frac{1-\beta}{1-\frac{1}{2} \beta}\left(\frac{\mathrm{d} L}{\mathrm{~d} t}\right)^{2}-\frac{\beta}{1-\frac{1}{2} \beta} \frac{P_{2}-P_{1}}{\rho} \\
& -\frac{\beta}{1-\frac{1}{2} \beta} g \sin \theta L+\frac{f}{2 D} \frac{1-\beta+\frac{1}{3} \beta^{2}}{\beta\left(1-\frac{1}{2} \beta\right)} L\left(\frac{\mathrm{d} L}{\mathrm{~d} t}\right)^{2}
\end{aligned}
$$

Define $\quad \mathrm{d} L / \mathrm{d} t:=w(L)<0, \quad \alpha:=2(1-\beta) /(1-\beta / 2), \quad$ and $f^{*}:=(f / 2 D)\left(1-\beta+\beta^{2} / 3\right) /\left(\beta-\beta^{2} / 2\right)$, use Eq. (12), and find the following linear first-order ODE for $w^{2}$

$$
\frac{\mathrm{d} w^{2}}{\mathrm{~d} L}+\left(\frac{\alpha}{L}-2 f^{*}\right) w^{2}=-\frac{2}{L} \frac{\beta}{1-\frac{1}{2} \beta} \frac{P_{2}-P_{1}}{\rho}-\frac{2 \beta}{1-\frac{1}{2} \beta} g \sin \theta
$$

The solution for the initial condition $w\left(L_{0}\right)=0$

$$
\begin{aligned}
& \frac{1-\frac{1}{2} \beta}{2 \beta} w^{2}=\frac{P_{2}-P_{1}}{\rho}\left(\frac{\Gamma\left(\alpha, 2 L f^{*}\right)}{\left(2 L f^{*}\right)^{\alpha}}-\frac{\Gamma\left(\alpha, 2 L_{0} f^{*}\right)}{\left(2 L_{0} f^{*}\right)^{\alpha}}\left(\frac{L_{0}}{L}\right)^{\alpha}\right) \mathrm{e}^{2 f^{*} L} \\
& \quad+g \sin \theta L\left(\frac{\Gamma\left(\alpha+1,2 L f^{*}\right)}{\left(2 L f^{*}\right)^{\alpha+1}}-\frac{\Gamma\left(\alpha+1,2 L_{0} f^{*}\right)}{\left(2 L_{0} f^{*}\right)^{\alpha+1}}\left(\frac{L_{0}}{L}\right)^{\alpha+1}\right) \mathrm{e}^{2 f^{*} L}
\end{aligned}
$$

is in terms of upper incomplete gamma functions $\Gamma$. The slug length $L$ is replaced by $L_{0}-\beta /(1-\beta) L_{\text {pipe }}$ (Eq. (10)), which is the solution for $L$ as a function of $L_{\text {pipe }}$ (to obtain the solution as 
function of the distance traveled by the slug front). The symbolic formula (16) for $v_{1}$ (instead of $w^{2}$ ) follows then directly from Eq. (A4).

\section{References}

[1] Hou, Q., Tijsseling, A. S., and Bozkuş, Z., 2014, "Dynamic Force on an Elbow Caused by a Traveling Liquid Slug," ASME J. Pressure Vessel Technol., 136(3), p. 031302.

[2] Bozkus, Z., and Wiggert, D. C., 1997, "Liquid Slug Motion in a Voided Line," J. Fluids Struct., 11(8), pp. 947-963.

[3] Bozkuş, Z., Baran, Ö., and Ger, M., 2004, "Experimental and Numerical Analysis of Transient Liquid Slug Motion in a Voided Line," ASME J. Pressure Vessel Technol., 126(2), pp. 241-249.

[4] Tijsseling, A. S., and Vardy, A. E., 2004, "Time Scales and FSI in Unsteady Liquid-Filled Pipe Flow," The 9th International Conference on Pressure Surges, S. J. Murray ed., Chester, UK, BHR Group, Cranfield, UK, pp. 135-150.

[5] Tijsseling, A. S., and Vardy, A. E., 2008, "Time Scales and FSI in Oscillatory Liquid-Filled Pipe Flow," The 10th International Conference on Pressure Surges, S. Hunt ed., Edinburgh, UK, BHR Group, Cranfield, UK, pp. 553-568.

[6] Young, H. D., and Freedman, R. A., 2014, University Physics, 13th ed., Section 8.6, Pearson Education, Harlow, UK.
[7] Bozkus, Z., 1991, "The Hydrodynamics of an Individual Transient Slug in a Voided Line," Ph.D. thesis, Department of Civil and Environmental Engineering, Michigan State University, East Lansing, MI.

[8] Heath, M. T., 2002, Scientific Computing, 2nd ed., McGraw-Hill, New York, Chap. 9.

[9] Chu, S. S., 2003, "Separated Flow in Bends of Arbitrary Turning Angles, Using the Hodograph Method and Kirchhoff's Free Streamline Theory," ASME J. Fluids Eng., 125(3), pp. 438-442.

[10] Hou, Q., Kruisbrink, A. C. H., Pearce, F. R., Tijsseling, A. S., and Yue, T. 2014, "Smoothed Particle Hydrodynamics Simulations of Flow Separation at Bends," Comput. Fluids, 90, pp. 138-146.

[11] Kayhan, B. A., and Bozkus, Z., 2011, "A New Method for Prediction of the Transient Force Generated by a Liquid Slug Impact on an Elbow of an Initially Voided Line,” ASME J. Pressure Vessel Technol., 133(2), p. 021701.

[12] Koppel, T., and Ainola, L., 2006, "Identification of Transition to Turbulence in a Highly Accelerated Start-Up Pipe Flow," ASME J. Fluids Eng., 128(4), pp. 680-686.

[13] He, S., Ariyaratne, C., and Vardy, A. E., 2008, "A Computational Study of Wall Friction and Turbulence Dynamics in Accelerating Pipe Flows," Comput. Fluids 37(6), pp. 674-689.

[14] He, S., Ariyaratne, C., and Vardy, A. E., 2011, "Wall Shear Stress in Accelerating Turbulent Pipe Flow,” J. Fluid Mech., 685, pp. 440-460.

[15] Annus, I., Koppel, T., Sarv, L., and Ainola, L., 2013, "Development of Accelerating Pipe Flow Starting From Rest,” ASME J. Fluids Eng., 135(11), p. 111204. 